\title{
PREDIÇÃO DAS PROPRIEDADES DE SATURAÇÃO DE FLUIDOS CRIOGÊNICOS
}

\author{
L.M. SOTINI ${ }^{1}$, P.F. ARCE-CASTILLO ${ }^{1}$ \\ ${ }^{1}$ Universidade de São Paulo, Escola de Engenharia de Lorena, Depto de Engenharia Química \\ E-mail para contato: parce@usp.br
}

\begin{abstract}
RESUMO - O trabalho apresentado neste artigo teve como propósito predizer a pressão de saturação para quatro fluidos criogênicos: nitrogênio, oxigênio, hélio e metano, utilizando o modelo termodinâmico de Peng-Robinson e ferramentas computacionais. Os resultados obtidos pela equação de estado de Peng-Robinson foram comparados com os dados experimentais (Design Institute for Physical Properties, DIPPR) e com resultados obtidos pelo método de redes neurais artificiais, a fim de determinar se a equação cúbica de estado consegue predizer a propriedade de saturação dos fluidos criogênicos. Obteve-se que, para o hélio, a equação de Peng-Robinson não apresentou bons resultados em termos de desvios na pressão de saturação, e, para os demais fluidos criogênicos foi possível predizer com certa eficácia, mas com desvios ligeiramente altos. Por outro lado, as pressões de vapor obtidas com as redes neurais artificiais ficaram muito próximas dos dados experimentais. Concluiu-se que é possível calcular a pressão de saturação para fluidos criogênicos usando a equação cúbica de estado de PengRobinson com certa eficiência, mas com erro maior do que pelo método de redes neurais artificiais, ocorrendo exceção para o hélio, que devido à proximidade do ponto triplo e seu ponto crítico, as convergências não são alcançados com o método de Newton-Raphson e por tanto a predição de propriedades de saturação não é a adequada nessas condições utilizando essa equação de estado.
\end{abstract}

\section{INTRODUÇÃO}

\subsection{Criogenia e Fluidos Criogênicos}

A criogenia, um ramo da física e da engenharia que estuda a produção e aplicação de materiais a temperaturas muito baixas (abaixo de $123 \mathrm{~K}$ ou $-150{ }^{\circ} \mathrm{C}$ ), atualmente vêm ganhando grande importância, com aplicações em diversas áreas, como por exemplo: liquefação de gases industriais; análise física de comportamento de materiais; no campo da medicina, com o uso de ressonância magnética e tomografia computadorizada; como sensores e sistemas de uso comercial, industrial, militar e espacial, dentre várias outras aplicações. (Jha, 2006)

Os fluidos criogênicos, que são os fluidos usados em tais operações, são, por definição, substâncias puras que à pressão atmosférica possuem ponto de ebulição inferior a $-40{ }^{\circ} \mathrm{C}$. Como exemplos, podemos citar: hélio $(\mathrm{He})$, nitrogênio $\left(\mathrm{N}_{2}\right)$, oxigênio $\left(\mathrm{O}_{2}\right)$, metano ou gás natural $\left(\mathrm{CH}_{4}\right)$, hidrogênio $\left(\mathrm{H}_{2}\right)$, neônio $(\mathrm{Ne})$, argônio (Ar), entre outros, dos quais os quatro primeiros apresentam maiores aplicações industriais. 
Em busca de uma maior eficiência nos processos criogênicos, faz-se necessário conhecer as propriedades termodinâmicas desses fluidos para calcular grandezas importantes desde o ponto de vista econômico, como calor e trabalho. Assim, as propriedades termodinâmicas como pressão, temperatura, volume específico, entalpia, entropia, energia interna e energia livre de Gibbs, precisam ser determinadas. Na predição de propriedades termodinâmicas, uma importante ferramenta são as equações de estado. Essas equações são relações matemáticas entre grandezas termodinâmicas de estado (como as citadas anteriormente), entre funções de estado de um sistema termodinâmico, ou que descrevem o estado de uma matéria sob determinadas condições físicas. (Valderrama, 2003; Michelsen e Mollerup, 2007; Terron, 2009).

\subsection{Redes Neurais Artificiais (RNA)}

Uma rede neural, um tipo de processador paralelamente distribuído, é constituída de unidades de processamento simples que têm a propensão natural para armazenar conhecimento experimental e torná-lo disponível para uso. Ela se assemelha ao cérebro em dois aspectos:

a) $\mathrm{O}$ conhecimento é adquirido pela rede a partir de seu ambiente através de um processo de aprendizagem.

b) Forças de conexão entre neurônios, conhecidas como pesos sinápticos, são utilizadas para armazenar o conhecimento adquirido.

A aprendizagem permite que a rede modifique sua própria estrutura (matriz de pesos), se adaptando até conseguir um algoritmo de execução. Este algoritmo é construído a partir das características extraídas dos exemplos com os que se realiza o treinamento. A aprendizagem consiste em fazer mudanças nos pesos das conexões entre os neurônios da rede até conseguir a resposta desejada. Pode-se dizer que o treinamento é o procedimento pelo qual a rede aprende, e que a aprendizagem é o resultado final desse processo, e também que o primeiro é um procedimento externo à rede, e o segundo, um procedimento ou atividade interna. Em outras palavras, em uma RNA treinada, o conjunto dos pesos determina o conhecimento dessa RNA e tem a propriedade de resolver o problema para o qual a RNA foi treinada (Zupan e Gasteiger, 1993).

\subsubsection{Redes Neurais Artificiais na Estimativa de Propriedades Termodinâmicas}

As RNA são utilizadas na estimativa das propriedades físico-químicas e termodinâmicas. Elas receberam diversos enfoques para descrever a estrutura molecular, incluindo fragmentos moleculares, índices topológicos, descritores calculados por métodos semi-empíricos, química quântica, coeficientes de distribuição ou partição, ponto de ebulição e pressão de vapor. Neste caso, serão aplicadas para estimar a pressão de vapor de fluidos criogênicos, utilizando diferentes variáveis para a predição e a correlação dos dados. Consiste em realizar um reconhecimento de padrões, buscar um padrão em uma série de exemplos, classificar os padrões, completar um sinal a partir de valores parciais ou reconstruir o padrão correto com base em uma visão distorcida. (Freeman e Skapura, 1991).

Neste trabalho, utilizando a equação cúbica de estado de Peng-Robinson, as pressões de saturação para o nitrogênio, oxigênio, hélio e metano são preditas. Por outro lado, utilizando 
redes neurais artificias, valores de pressão de saturação desses fluidos criogênicos são estimados. Os resultados de ambos os métodos serão comparados com os dados experimentais (DIPPR).

\section{MODELO TERMODINÂMICO: EQUAÇÃO DE ESTADO DE PENG- ROBINSON}

A equação de estado de Peng-Robinson (Peng e Robinson, 1976) é uma equação cúbica capaz de correlacionar propriedades termodinâmicas de substâncias puras e de misturas, permitindo o cálculo de propriedades termodinâmicas de interesse de substâncias simples e capaz de predizer propriedades de equilíbrio de fase (líquido-vapor, líquido-líquido, sólido-líquido, etc). A equação de Peng-Robinson, aplicada a uma substância pura, pode ser expressa principalmente de duas maneiras: em função de pressão (P), volume (v) e temperatura $(\mathrm{T})$, ou em função do fator de compressibilidade $(\mathrm{z})$. A equação se pode expressar em termos de PTv da seguinte maneira:

$$
P=\frac{R T}{v-b}-\frac{a_{C}}{v(v+b)+b(v-b)}
$$

onde $\mathrm{P}$ é a pressão do sistema, $\mathrm{R}$ é a constante universal dos gases, $\mathrm{T}$ é a temperatura absoluta, $\mathrm{v}$ é o volume molar, e $a_{c}$ e b são constantes dependentes das propriedades críticas e podem ser obtidas com as seguintes equações:

$$
a_{C}=\frac{0.45724 R^{2} T_{c}^{2} \alpha(T)}{P_{c}}, \quad b=\frac{0.07780 R T_{c}}{P_{c}}
$$

Na Equação 2 temos que R é a constante universal dos gases, $T_{c}$ é a temperatura crítica, $P_{c}$ é a pressão crítica e $\alpha(T)$ é uma constante dependente do fator acêntrico $\left(\mathrm{w}_{\mathrm{i}}\right)$ e da temperatura reduzida $\left(T_{r, i}\right)$, podendo ser calculada da seguinte forma:

$$
\alpha(T)=\left[1+m_{i}\left(1-\sqrt{T_{r, i}}\right)\right]^{2} \quad, \quad m_{i}=0.37464+1.54226 w_{i}-0.26992 w_{i}^{2}
$$

A equação de Peng-Robinson pode também ser expressa em termos do fator de compressibilidade. Precisam-se calcular apenas as constantes A e B (adimensionais), que variam em função das constantes a e b, e podem ser calculadas da seguinte maneira:

$$
A=\frac{a P}{R^{2} T^{2}} \quad, \quad B=\frac{b P}{R T}
$$

O fator de compressibilidade pode então ser determinado pela seguinte equação:

$$
z^{3}-(1-B) z^{2}+\left(A-2 B-3 B^{2}\right) z-A B+B^{2}+B^{3}=0
$$

Sendo que das raízes obtidas da Equação 5, para o caso de três raízes reais, apresentam significado físico a menor raiz maior que zero, correspondente ao fator de compressibilidade 
do líquido saturado, e a maior raiz, correspondente ao fator de compressibilidade do vapor saturado. No caso de única raiz real, o sistema se encontra no estado gasoso.

\section{METODOLOGIA - CRITÉRIO DE EQUILÍBRIO}

As propriedades de saturação correspondem às propriedades no ponto de equilíbrio entre fases, e o critério de equilíbrio das fases líquido e vapor é a igualdade das fugacidades ou coeficientes de fugacidade da fase líquida e vapor (Equação 6), sendo possível assim criar um algoritmo para o cálculo da pressão de saturação, tendo-se como critério que a pressão de saturação será a pressão na qual as fases líquida e vapor apresentam valores iguais de fugacidade ou coeficientes de fugacidade, com certa tolerância especificada (Sandler, 2006):

$$
f_{i}^{L}=f_{i}^{V} \quad, \quad \phi_{i}^{L}=\phi_{i}^{V}
$$

O coeficiente de fugacidade obtido a partir da equação de estado de Peng-Robinson, é apresentado na seguinte equação:

$$
\ln \phi=(z-1)-\ln (z-B)+\frac{A}{2 \sqrt{2} B} \ln \left(\frac{z+(1-\sqrt{2}) B}{z+(1+\sqrt{2}) B}\right)
$$

onde $\phi$ é o coeficiente de fugacidade, z é o fator de compressibilidade, A e B são as constantes adimensionais de Peng-Robinson. Para a predição das propriedades de saturação, criou-se um algoritmo em MATLAB, em que se fornecem como parâmetros de entrada as propriedades físicas e críticas do fluido (temperatura e pressão do ponto triplo, temperatura e pressão do ponto crítico e fator acêntrico), e a temperatura (de saturação) na qual se deseja obter a pressão de saturação, e um valor inicial de pressão (chute inicial). Em seguida, o algoritmo calcula as constantes necessárias para o cálculo do fator de compressibilidade, usando as Equações de 2 até 5. Programou-se para, usando a Equação 5, calcular as raízes para o fator de compressibilidade, e através de condicionais, selecionar as raízes válidas para o líquido e o vapor. Após isso, o programa calcula os coeficientes de fugacidade para o líquido e o vapor e faz uma comparação, pois o critério de equilíbrio é a igualdade entre as fugacidades ou coeficientes de fugacidade (Equação 6) dentro de uma certa tolerância (Sandler, 2006).

Usou-se como critério de comparação que $\left|\mathrm{f}^{\mathrm{L} / \mathrm{f}^{V}}-1\right|<0,0001$. Se esse critério for atendido, a pressão corresponderá à pressão de saturação, e o programa apresentará o resultado na tela. Caso a condição não seja satisfeita, o programa efetua uma correção para a pressão, sendo a nova pressão igual ao valor antigo de pressão multiplicado pela razão entre as fugacidades do líquido e vapor. O programa repetirá os cálculos até que o critério de comparação seja satisfeito (Sandler, 2006). Deve-se atentar ao fato de que os cálculos são válidos para a região de saturação líquido-vapor, portanto os valores de temperatura e pressão devem estar entre o ponto triplo e o ponto crítico. Além disso, o chute inicial de pressão é importante, pois se devem ter duas raízes reais válidas, uma para o vapor e outra para o líquido. 


\section{RESULTADOS E DISCUSSÃO}

Neste trabalho, para efetuar os cálculos utilizou-se dados das propriedades físicas e críticas dos fluidos criogênicos (DIPPR, 2000), os quais são apresentados na Tabela 1.

Tabela 1 - Propriedades físicas e críticas de fluidos criogênicos

\begin{tabular}{|l|c|c|c|c|c|c|}
\hline \multirow{2}{*}{$\begin{array}{l}\text { Fluido } \\
\text { Criogênico }\end{array}$} & \multirow{2}{*}{$\begin{array}{c}\text { Temp. ebulição } \\
(1 \mathrm{~atm})(\mathrm{K})\end{array}$} & \multirow{2}{*}{$\begin{array}{c}\text { Fator } \\
\text { acêntrico }(\mathrm{w})\end{array}$} & \multicolumn{2}{|c|}{ Ponto triplo } & \multicolumn{2}{|c|}{ Ponto crítico } \\
\cline { 4 - 7 } & 4,224 & $-0,39003$ & 1,763 & 0,01478 & 5,2 & 2,275 \\
\hline Hélio & 77,344 & 0,03772 & 63,149 & 0,1252 & 126,2 & 34,0 \\
\hline Nitrogênio & 90,188 & 0,02218 & 54,361 & 0,0015 & 154,58 & 50,43 \\
\hline Oxigênio & 111,66 & 0,01155 & 90,694 & 0,11696 & 190,564 & 45,99 \\
\hline Metano & &
\end{tabular}

Segundo a Metodologia, efetuaram-se cálculos para o hélio, metano, nitrogênio e oxigênio em várias temperaturas entre o ponto triplo e o ponto crítico. Os resultados obtidos com a equação de Peng-Robinson e as Redes Neurais foram comparados com os dados experimentais (Tabela 2). Os erros foram calculados de acordo ao seguinte critério:

$$
\text { Erro }=\frac{P_{i, \text { calc }}^{S A T}-P_{i, \exp }^{S A T}}{P_{i, \exp }^{S A T}} * 100
$$

Tabela 2 - Resultados obtidos com a equação de Peng-Robinson (EdE PR) e Redes Neurais Artificais (RNA)

\begin{tabular}{|c|c|c|c|c|c|c|}
\hline \multirow{3}{*}{$\begin{array}{c}\text { Fluido } \\
\text { Criogênico }\end{array}$} & \multirow{3}{*}{$\mathrm{T}(\mathrm{K})$} & \multicolumn{3}{|c|}{ PSAT (bar) } & \multirow{2}{*}{\multicolumn{2}{|c|}{ Erro (\%) }} \\
\hline & & Experimental & Calc & & & \\
\hline & & DIPPR & EdE PR & RNA & EdE PR & RNA \\
\hline \multirow{5}{*}{ Hélio } & 4,2 & 0,9966 & 0,6029 & 1,0069 & 39,51 & 1,03 \\
\hline & 3,6 & 0,5335 & 0,1963 & 0,5376 & 63,20 & 0,78 \\
\hline & 1,8 & 0,0168 & 0,00005218 & 0,0164 & 99,69 & 2,65 \\
\hline & 2,4 & 0,0838 & 0,003569 & 0,0785 & 95,74 & 6,33 \\
\hline & 5,2 & 2,2845 & Não encontrado & 2,2632 & ---- & 0,93 \\
\hline Metano & 161,0 & 16,5647 & 15,6234 & 16,5945 & 5,68 & 0,18 \\
\hline \multirow{3}{*}{ Nitrogênio } & 92,0 & 4,2593 & 3,7039 & 4,2782 & 13,04 & 0,44 \\
\hline & 90,0 & 3,6029 & 3,093 & 3,6201 & 14,15 & 0,48 \\
\hline & 98,0 & 6,7532 & 6,0811 & 6,7656 & 9,95 & 0,18 \\
\hline \multirow{6}{*}{ Oxigênio } & 86,0 & 0,6379 & 0,4608 & 0,6139 & 27,77 & 3,77 \\
\hline & 146,0 & 36,0053 & 35,3916 & 36,0398 & 1,70 & 0,10 \\
\hline & 116,0 & 8,0520 & 7,1262 & 8,0707 & 11,50 & 0,23 \\
\hline & 107,0 & 4,3920 & 3,7131 & 4,3854 & 15,46 & 0,15 \\
\hline & 101,0 & 2,7578 & 2,2484 & 2,7482 & 18,47 & 0,35 \\
\hline & 71,0 & 0,0750 & 0,0447 & 0,0785 & 40,39 & 4,69 \\
\hline
\end{tabular}

Da Tabela 2, nota-se que para o hélio, a equação de Peng-Robinson não foi eficiente, apresentando desvios muito grandes entre o valor experimental e o calculado, portanto, esta equação não pode ser utilizada para modelar as propriedades do hélio. Tal ineficiência pode 
ser devido a peculiaridades das características deste elemento, que apresenta intervalo de temperatura muito pequeno entre o ponto triplo e o ponto crítico, baixas pressões de vapor e fator acêntrico negativo, o que faz com que a equação de estado não se adeque muito bem a esse fluido. Para o metano, nitrogênio e oxigênio, o modelo se mostrou capaz de calcular a pressão de saturação, mas com certa limitação, apresentando erros maiores em temperaturas e pressões mais baixas, próximas ao ponto triplo. Comparando-se o método da equação de Peng-Robinson com o de redes neurais artificiais, foi possível perceber que os cálculos usando a equação de estado apresentaram maiores desvios com relação ao dado experimental do que pelo método de redes neurais, tornando-se o método de redes neurais mais eficiente. Contudo, a predição feita pela equação de Peng-Robinson, pode ser usada como alternativa para predizer as propriedades de saturação dos fluidos criogênicos, por se tratar de um método mais simples que o de redes neurais e ter apresentado resultados mais próximos dos determinados experimentalmente a temperaturas e pressões mais altas.

\section{CONCLUSÕES}

Do estudo realizado, conclui-se que a predição usando a equação de Peng-Robinson não apresenta bons resultados para o hélio, devido a características especiais do elemento, e que, para o metano, nitrogênio e oxigênio apresenta resultados aceitáveis, especialmente sob temperaturas e pressões mais próximas do ponto crítico, apresentando menor eficiência do que o método de redes neurais, mas podendo se constituir numa alternativa para estimar as propriedades termodinâmicas desses fluidos criogênicos.

\section{REFERÊNCIAS BIBLIOGRÁFICAS}

DIPPR Information and Data Evaluation Manager. Version 1.2.0, 2000.

FREEMAN, J. A.; SKAPURA D. M. Neural Networks - Algorithms, Applications, and Progaming Techniques. USA Addison Wesley - Publishing Company, 1991.

JHA, A.R. Cryogenic Technology and Applications. Elsevier Inc., New York, 2006.

MICHELSEN, M.L.; MOLLERUP, J.M. Thermodynamic Models : Fundamentals \& Computational Aspects. Tie Line Publications, 2da edicao, Dinamarca, 2007.

PENG, D.Y.; ROBINSON, D.B. A new two constant equation of state. Ind. Eng. chem. Fundam., v. 15, p. 59-64, 1976.

SANDLER, S. I. Chemical, Biochemical and Engineering Thermodynamics, $4^{\text {th }}$ edition, John Wiley \& Sons, 2006

TERRON, L.R. Termodinâmica Química Aplicada. Ed. Manole, Barueri, São Paulo, 2009.

VALDERRAMA, J.O. The state of the Cubic Equations of State. Ind. Eng. Chem. Res., v. 42, p. 1603-1618, 2003.

ZUPAN, J.; GASTEIGER, J. Neural Networks for Chemists, VCH Publishers, NY-USA, 1993. 